\title{
Update Breast Cancer 2018 (Part 3) - Genomics, Individualized Medicine and Immune Therapies - in the Middle of a New Era: Prevention and Treatment Strategies for Early Breast Cancer
}

Update Mammakarzinom 2018 (Teil 3) - Genomforschung, individualisierte Medizin und Immuntherapien - mitten in einer neuen Ära: Prävention und Therapie des frühen Mammakarzinoms

\section{(ब) $(8 \ominus$}

Authors

Achim Wöckel ${ }^{1}$, Michael P. Lux ${ }^{2}$, Wolfgang Janni ${ }^{3}$, Andreas D. Hartkopf ${ }^{4}$, Naiba Nabieva ${ }^{2}$, Florin-Andrei Taran ${ }^{4}$, Friedrich Overkamp ${ }^{5}$, Peyman Hadji ${ }^{6}$, Hans Tesch ${ }^{7}$, Johannes Ettl ${ }^{8}$, Diana Lüftner ${ }^{9}$, Volkmar Müller ${ }^{10}$, Manfred Welslau ${ }^{11}$, Erik Belleville ${ }^{12}$, Sara Y. Brucker ${ }^{4}$, Florian Schütz ${ }^{13}$, Peter A. Fasching ${ }^{2}$, Tanja N. Fehm ${ }^{14}$, Andreas Schneeweiss ${ }^{13,15}$, Hans-Christian Kolberg ${ }^{16}$

\section{Affiliations}

1 Department of Gynecology and Obstetrics, University Hospital Würzburg, Germany

2 Erlangen University Hospital, Department of Gynecology and Obstetrics, Comprehensive Cancer Center ErlangenEMN, Friedrich-Alexander University Erlangen-Nuremberg, Erlangen, Germany

3 Department of Gynecology and Obstetrics, Ulm University Hospital, Ulm, Germany

4 Department of Obstetrics and Gynecology, University of Tübingen, Tübingen, Germany

5 OncoConsult Hamburg GmbH, Hamburg, Germany

6 Department of Bone Oncology, Nordwest Hospital,

Frankfurt, Germany

7 Oncology Practice at Bethanien Hospital Frankfurt, Frankfurt, Germany

8 Department of Obstetrics and Gynecology, Klinikum rechts der Isar, Technical University of Munich, Munich, Germany

9 Charité University Hospital, Berlin, Campus Benjamin Franklin, Department of Hematology, Oncology and Tumour Immunology, Berlin, Germany

10 Department of Gynecology, Hamburg-Eppendorf University Medical Center, Hamburg, Germany

11 Onkologie Aschaffenburg, Hämatolo-Onkologische Schwerpunktpraxis am Klinikum Aschaffenburg, Aschaffenburg, Germany

12 ClinSol GmbH \& Co KG, Würzburg, Germany

13 Department of Obstetrics and Gynecology, University of Heidelberg, Heidelberg, Germany

14 Department of Gynecology and Obstetrics, University Hospital Düsseldorf, Düsseldorf, Germany
15 National Center for Tumor Diseases, Division Gynecologic Oncology, University Hospital Heidelberg, Heidelberg, Germany

16 Department of Gynecology and Obstetrics, Marienhospital Bottrop, Bottrop, Germany

Key words

breast cancer, treatment, metastases, CDK4/6, PD1/PDL1,

studies, risk, prevention

Schlüsselwörter

Mammakarzinom, Behandlung, Metastasen, CDK4/6, PD1/

PDL1, Studien, Risiko, Prävention

received 9.8.2018

accepted 23.8.2018

Bibliography

DOI https://doi.org/10.1055/a-0715-2821

Geburtsh Frauenheilk 2018; 78: 1110-1118 @ Georg Thieme

Verlag KG Stuttgart · New York | ISSN 0016-5751

Correspondence

Peter A. Fasching, MD

Erlangen University Hospital, Department of Gynecology and Obstetrics, Comprehensive Cancer Center Erlangen EMN,

Friedrich Alexander University of Erlangen-Nuremberg Universitätsstraße 21-23, 91054 Erlangen, Germany peter.fasching@uk-erlangen.de

$\Theta$ Deutsche Version unter: https://doi.org/10.1055/a-0715-2821 


\section{ABSTRACT}

In primary early breast cancer, the aim of treatment planning is to obtain an increasingly better understanding of the disease. The identification of patients with an excellent prognosis could help this group avoid unnecessary treatments. Furthermore, the planning of treatment is becoming increasingly patient-focussed. There is a growing understanding of those patients who benefit particularly from chemotherapy, as well as of those who could benefit from immunotherapy. Studies conducted on immunotherapies will be published shortly. Smaller individual studies offer an initial insight into the efficacy of checkpoint inhibitors (anti-PD1/PDL1 therapies). Not least, one of the largest breast cancer studies of all times has recently come to an end. The use of a multigene test has shown that it is sufficient to identify patients with such a good prognosis that chemotherapy is unnecessary. This review article is intended to summarise the current studies and give an outlook on current developments.

\section{Introduction}

One of the fundamental principles of medical practice, "primum non nocere", Latin for "first, do no harm" is as topical in 2018 as ever. This applies in particular to cancers. The other principles of this Hippocratic tradition such as "second, be careful" and "third, cure" also have their correlates in the current study results, guidelines and treatment recommendations [1-3]. For cancers, this means that the identification of patients with a good and poor prognosis, with good and poor treatment responses and with severe vs. mild adverse reactions continues to be one of the main areas of research and of efforts to transpose these findings into clinical practice. Current developments are increasingly heading in this direction with the presentation in the last few months of a series of studies at large international congresses such as that of the American Society of Oncology 2018, the American Association of Cancer Research 2018, the Congress of the German Society for Senology and the Cancer Congress 2018, as well as in international publications.

\section{Prevention}

\section{Individualised risk prediction}

It is still the case that only some breast cancers can be explained by risk factors. In the last few years, work has been undertaken in particular on genetic risk factors and mammographic density. A huge amount of data has been generated in the area of genetic risk factors in the last 10 years, which explain about 38\% in total of a two-fold increase in familial relative risk [4-7]. Of this figure, about $20 \%$ is explained by moderate to high penetrance genes (BRCA1, BRCA2, CHEK2, PALB2, etc.) and $18 \%$ by frequent risk vari-

\section{ZUSAMMENFASSUNG}

Beim primären, frühen Mammakarzinom zielt die Behandlungsplanung auf ein immer besseres Verständnis der Erkrankung ab. Die Identifikation von Patientinnen mit einer exzellenten Prognose könnte dieser Gruppe helfen, unnötige Therapien zu vermeiden. Weiterhin wird die Planung der Therapie immer weiter auf die Patientin abgestimmt. Das Wissen über Patientinnen, die besonders von einer Chemotherapie profitieren, wächst genauso wie das Wissen um Patientinnen, die von einer Immuntherapie profitieren könnten. Hinsichtlich der Immuntherapien stehen die durchgeführten Studien kurz vor der Publikation. Einzelne kleinere Studien bieten einen ersten Einblick in die Wirksamkeit der Checkpoint-Inhibitoren (Anti-PD1/PDL1-Therapien). Nicht zuletzt konnte kürzlich eine der größten Brustkrebsstudien aller Zeiten zu Ende geführt werden. Die Anwendung eines Multigentests konnte zeigen, dass er ausreicht, um Patientinnen mit einer so guten Prognose zu identifizieren, dass keine Chemotherapie nötig ist. Dieser Review-Artikel soll die aktuellen Studien zusammenfassen und einen Ausblick der gegenwärtigen Entwicklungen geben. ants, about 173 of which have been validated and published [4$30]$. It is also estimated that a further $23 \%$ of the two-fold increase in familial relative risk can be explained by common variants that have not yet been described [7]. This knowledge is utilised to develop what are known as polygenic risk scores or prediction models for the individual breast cancer risk or specific subtypes [3136], which can then be converted into individualised early detection measures, albeit only in studies to date [32,37-41]. Germline variants are increasingly appearing to play a role in the choice of therapy and prediction of therapeutic effectiveness, not only in risk prediction but also in treatment [42-46].

\section{New medicinal prevention strategies}

In terms of actual primary prevention, it has recently been demonstrated that the RANKL/RANK/OPG pathway plays a particular role in BRCA1 mutation carriers [47-50]. Based on previous studies involving, amongst others, a cohort of BRCA1 mutation carriers who responded to treatment with denosumab with a reduction in the proliferation of breast epithelial cells [47], a prevention study is now being conducted with denosumab in BRCA1 mutation carriers [51]. If effective, this therapy would have a good benefit/risk profile with an acceptable side effect profile for this individual risk population.

\section{New local radiotherapeutic prevention strategies}

For breast cancer patients with the BRCA1/2 mutation, the question also arises of how to deal with the risk of contralateral breast cancer. The cumulative risk in the first 20 years following breast cancer is about $40 \%$ [52]. For these patients, the option of a contralateral mastectomy is mooted $[53,54]$. A further experimental option, contralateral radiation, has been evaluated in a recently published study [55]. This phase II study enrolled 162 patients 
with a BRCA1/2 mutation, 81 of whom had decided for and 81 against radiation of the contralateral breast [55]. At a median follow-up of 60 months, 9 patients in the non-irradiated group had developed contralateral breast cancer, whereas this was the case in only 2 patients in the irradiated group ( $p=0.027)$. Interestingly, the 9 relapses in the non-irradiated group occurred after a median of 24 months, whereas the 2 relapses in the irradiated group occurred after 80 and 109 months [55]. There were no early or late complications of irradiation in the irradiated group so that contralateral radiation for patients with a BRCA1/2 mutation could provide an alternative to prophylactic contralateral mastectomy.

\section{Early Breast Cancer - Local Therapy}

Local therapy, in other words the removal of all tumour cells from the breast and the locoregional lymph nodes, is the basis of primary treatment of breast cancer. Some aspects of irradiation of the locoregional lymph nodes continue to be investigated. The EORTC-22922/10925 study investigated the value of irradiation of the medial supraclavicular and the internal mammary lymph nodes in breast cancer of clinical stages I-III [56]. The analyses of the 15-year follow-up have now been presented [57]. Four thousand and four patients with axillary lymph node involvement and/ or medial tumour localisation were enrolled in the study. Patients were randomised for or against irradiation of the above-mentioned lymph node stations. About half the patients (55.6\%) were included with lymph node involvement, whereas the other patients had negative lymph nodes but a medial tumour localisation. The primary aim of the study was to identify a difference of $4.0 \%$ in 10-year overall survival between the two arms, but this aim was not achieved with a marginally non-significant benefit of $1.6 \%$ ( $p=0.056)$ [56].

In the analysis that has now been published with a median follow-up of 15.7 years, there was a somewhat greater numerical benefit of $2.4 \%$ in terms of overall survival for extensive irradiation, but this difference was still non-significant ( $p=0.358$ ) [57]. Breast cancer mortality was significantly improved by $3.9 \%$ $(p=0.005)$ and the relapse rate by $2.6 \%(p=0.024)$ [57], but at the present time the authors still have no explanation as to why this does not convert into a significant overall survival benefit [57]. Before the extensive subgroup analyses announced by the authors are published, therefore, it is not possible to evaluate definitively either the value of more intensive irradiation as a whole or the question of which patients benefit in particular.

It has been known for some time that radiotherapy of tumours does not just have a local effect [58]. The effect whereby irradiation can not only achieve a local response but also exert an action on distant, non-irradiated regions is known as an "abscopal effect". The underlying mechanisms are not well understood and the effect has not been used therapeutically to date [58]. As the suspected effects are immunological in nature, it would be possible to attempt to utilise these effects for cancer therapy in combination with new, immunological therapies.

A recently presented phase II study on the combination of irradiation and pembrolizumab in metastatic triple-negative breast cancer has shown promising results here [59]. Even if the group of patients evaluable after 13 weeks was small with a total of 9 , the response rate of $33 \%$ outside the irradiated localisations and the persistence of a response for up to 40 weeks showed a clear difference from the expected response rate of just $5-7 \%$ in such a cohort with a median of 3 cytotoxic treatments prior to inclusion in the study. This is therefore a further indication of the possible effects of the combination of radiation and immunotherapy, for which promising results are already available $[60,61]$.

\section{Early Breast Cancer - Systemic Treatment of the Premenopausal Patient}

\section{Data on aromatase inhibitors is growing}

The adjuvant use of tamoxifen (TAM) in premenopausal women with hormone receptor-positive breast cancer is one of the most effective treatment options [62]. As the most effective treatment, aromatase inhibitors (Al) are one of the standards in postmenopausal patients [63]. For premenopausal patients, some studies have been conducted that have evaluated aromatase inhibitors with concomitant ovarian function suppression [64-66].

A recent analysis of the SOFT and TEXT study has now shown that the additional use of ovarian function suppression (OFS, e.g. by administration of a $\mathrm{GnRH}$ analogue) may be considered in women who continue to be or become premenopausal again within 8 months of receiving chemotherapy. In a current analysis of the 8-year data from the two studies, this procedure significantly improves disease-free and overall survival [66]. If an AI is used instead of TAM, the risk of recurrence is further reduced by $2-3 \%$, although no effect on overall survival has been seen here with a clinically relevant increase in morbidity [66].

Similarly, a risk-adapted analysis of distant recurrence-free survival of HER2-negative patients from the SOFT and TEXT studies has recently been published [67]. A composite recurrence risk index (CRRI) was calculated for each patient based on age, node status, tumour size, grading, ER and PR status, as well as Ki-67 expression. Whereas the distant recurrence risk was reduced by $3 \%$ in the total population by the use of an AI+OFS compared with TAM + OFS, in patients with a high clinical risk the figure was $15 \%$ [67]. TAM + OFS improved the distant recurrence-free survival of women with a high risk by $10 \%$ compared with TAM alone. In patients receiving TAM only, higher grade side effects occurred in $25 \%$ of cases; that figure was $31 \%$ of women in the TAM + OFS group and $32 \%$ in the $\mathrm{Al}+$ OFS group [67].

Noh et al. tackled a similar question in the ASTRRA study [68]. In this case, the menopausal status of 1483 initially premenopausal women under 45 years of age was followed up clinically and by laboratory measurements after completion of adjuvant or neoadjuvant chemotherapy. Definitely premenopausal women received 5 years of TAM vs. 5 years of TAM +2 years OFS. Twenty-four months after the end of chemotherapy $>90 \%$ of all study participants were premenopausal (again). In total, 1282 patients were randomised. At a median follow-up of 63 months, $88 \%$ of patients who had received TAM alone were recurrence-free. In the TAM + OFS group, however, this was the case with $91 \%$ of patients $(p=0.033)$. 
Both analyses confirm the current recommendation of the S3 guideline [69] that the combination of endocrine therapy with OFS can be considered only in premenopausal women with a high risk and a premenopausal status post-chemotherapy, since the increased adverse effect rate must be taken into consideration, particularly in terms of quality of life and compliance. In view of the increased rate of adverse effects, the lack of effect on overall survival and the slight reduction only in the recurrence rate, TAM ( \pm OFS) should only be replaced by an Al + OFS in individual cases (e.g. in the presence of contraindications). Endocrine therapy with TAM therefore remains the standard treatment of premenopausal women with early breast cancer.

\section{Early Breast Cancer - Systemic Treatment with Denosumab}

In terms of the adjuvant use of bisphosphonates, the Oxford meta-analysis resulted in a paradigm shift in international guidelines [70]. Consistent with many individual studies, this revealed a $34 \%$ reduction in the relative risk of occurrence of bone metastases and a $17 \%$ reduction in mortality in women with hormone receptor-positive breast cancer on hormone-deprivation therapy or who were postmenopausal and thus confirms the breast cancerspecific benefits of osteoporosis therapy "only".

In terms of the monoclonal antibody denosumab (Dmab), only one interim analysis of the ABCSG-18 study was available at the time [71]. Against this background, the analysis of the D-CARE study and the results of the ABCSG-18 study were expected to provide an explanation of the possible adjuvant use of Dmab.

Coleman et al. studied the adjuvant effect of Dmab vs. placebo on bone metastasis-free survival (BMFS) and various other secondary endpoints (DFS, OS) in the D-CARE study in 4509 premenopausal and postmenopausal women with a high recurrence risk [72]. Following neoadjuvant/adjuvant $\mathrm{CHT}$, randomisation was performed $<12$ weeks postoperatively. Predominantly women with hormone receptor-positive, HER2-negative, node-positive breast cancer G 2-3 were enrolled. More than 95\% received adjuvant $\mathrm{CHT}$, more than $90 \%$ of the hormone receptor-positive patients an $\mathrm{Al}$ and $79 \%$ of the HER2-positive patients corresponding anti-HER2 treatment. The dose-dense regimen with 6-monthly administration followed by quarterly administration of $120 \mathrm{mg}$ Dmab vs. placebo should also be highlighted. Because of the unexpectedly low recurrence rate, an amendment was made with a switch from an event-driven to a time-driven analysis. The results showed no significant differences in terms of primary and secondary endpoints (BMFS, DFS, OS). In terms of adverse reactions, 122 episodes of osteonecrosis of the jaw (ONJ) occurred with Dmab versus 4 with placebo as well as 9 vs. 0 atypical femoral fractures (AFF). In summary, adjuvant denosumab administration demonstrated no benefit in the population studied with an unacceptably high adverse effect rate overall.

Gnant et al. presented the results of the ABCSG-18 study after a median observation period of 73 months [73]. The effect of $60 \mathrm{mg}$ Dmab (every 6 months) was studied vs. placebo in 3425 postmenopausal, hormone-receptor-positive women with breast cancer on adjuvant Al therapy with a low recurrence risk overall.
The primary endpoint was the time to the first clinical osteoporosis-related fracture and was achieved impressively and markedly earlier than expected with an RR of $50 \%$. Because of the unexpectedly rapid and marked reduction in fractures, on the advice of the IDMC/SC enrolled patients were offered the opportunity of unblinding to allow them to change from placebo to Dmab, if necessary, for a period of 3 years (open-label phase). This option was taken up by 278 women, 252 of whom switched from placebo to Dmab. For this reason, the secondary endpoint DFS (OS and BMFS were not presented) was analysed descriptively only. The mean age of the study population was 64 years, > 70\% had T1-2, nodenegative, invasive ductal breast cancer and exhibited G1-2 tumours. All patients were hormone-receptor positive, >90\% were HER-2 positive and $>75 \%$ received neoadjuvant or adjuvant $\mathrm{CHT}$.

A hazard ratio of $0.82(0.69-0.98), p<0.025$ (log-rank) was found in terms of the secondary endpoint DFS in a descriptive analysis after a median observation period of 73 months. Because of the unexpectedly high fracture reduction and the offer of the option of an early switch from placebo to Dmab, a series of further analyses was undertaken (e.g. excluding the above-mentioned women in the crossover group), all of which confirmed the above-mentioned risk reduction of DFS along the same lines. This result was most pronounced when less than 3 months had elapsed between the start of Al therapy and the first administration of Dmab. A breakdown of the DFS results revealed a numerical superiority only in non-histologically confirmed distant metastases (DFS) or secondary invasive cancers (not breast cancer), while in terms of local recurrences, DCIS, contralateral breast cancers and histologically confirmed distant metastases (DFS) there were no differences between Dmab and placebo. In terms of adverse effects, there were no significant group differences [73]. In the ABCSG-18 there were no cases of osteonecrosis of the jaw (ONJ) or atypical femoral fractures (AFF). In summary, in addition to the previously published significant reduction in osteoporosisrelated clinical fractures, the ABCSG-18 study showed an improvement in DFS. This superiority was particularly apparent in terms of non-histologically confirmed distant metastases (DFS) and secondary invasive carcinomas (not breast cancer).

At first sight, these studies appear to show completely contradictory results. However, marked differences are apparent in the inclusion criteria of the two studies. Whereas pre- and postmenopausal women with a high risk of recurrence were included in the D-CARE study, in the ABCSG-18 study only postmenopausal women with a low recurrence risk were enrolled. Furthermore, in D-CARE a dose-dense administration of $120 \mathrm{mg}$ Dmab was given, whereas in the ABCSG-18 study only $60 \mathrm{mg}$ every 6 months was used. Both studies have undergone relevant protocol changes due to the low recurrence rate in the D-CARE study and the unexpectedly high fracture reduction in the ABCSG-18 study. Despite all the study-specific differences described above, the marked discrepancy in the study results continues to be surprising and inexplicable. On the basis of the D-CARE study, the adjuvant use of $120 \mathrm{mg}$ Dmab cannot be recommended at present, particularly because of the high adverse effect spectrum. In postmenopausal women on Al treatment, the fracture-reducing effect of $60 \mathrm{mg}$ Dmab every six months is undisputed. On the basis of the ABCSG-18 study, a positive effect on DFS may be assumed. 


\section{Early Breast Cancer - Treatment of the HER2-Positive Patient}

The survival of patients with early breast cancer with neoadjuvant or adjuvant chemotherapy is similar [74]. However, nowadays neoadjuvant chemotherapy is often given precedence if there is a clear indication for postoperative chemotherapy. Several studies have shown in HER2-positive and triple-negative tumours in particular that pathological complete remission ( $P C R)$ is a good surrogate marker for prognosis [75-77]. The choice of optimal neoadjuvant therapy in HER2-positive tumours is currently the subject of intense clinical research. Following the pioneering results with trastuzumab in adjuvant and neoadjuvant therapy, HER2-specific therapy is the standard. However, what are the optimal combination partners? In the Neosphere study, dual blockade with trastuzumab and pertuzumab in combination with chemotherapy showed a significantly higher pCR than trastuzumab alone [78]. However, in smaller tumours, in the absence of lymph node involvement and in "triple-positive tumours" (ER+/PR+/HER2+), other therapeutic concepts along the lines of de-escalation to reduce toxicity are under discussion.

In the phase II study PerELISA, a combination of trastuzumab, lapatinib and letrozole was tested in HER2-positive patients in an adaptive design [79]. Patients received 2-week therapy with lapatinib first of all, followed by a rebiopsy to evaluate Ki-67. Patients who had a fall in Ki-67 of more than $20 \%$ then received a combination of lapatinib, trastuzumab and pertuzumab for 5 cycles. Patients without a fall in $\mathrm{Ki}-67$ were treated with trastuzumab, pertuzumab and paclitaxel. Forty-four of 64 patients (69\%) exhibited a Ki-67 response after 2 weeks and underwent surgery following therapy with lapatinib, trastuzumab and pertuzumab. The pCR rate of this group was $20.5 \%$ (9 patients). The PCR rate was significantly higher in the "HER2 enriched" intrinsic subtype group than in the other subtypes ( 45.5 vs. $13.8 \%, p=0.042$ ) [79]. The intrinsic subtype also correlated with the Ki-67 response. The PerELISA study thus achieved the main endpoint in that chemotherapy-free treatment in an adaptive design showed a high response.

In the search for predictive biomarkers, the intrinsic HER2 enriched (HER2-E) subtype is a particular focus of attention. In a retrospective analysis, the two neoadjuvant studies PAMELA and TBCRC006 were analysed in this regard [80]. All patients received neoadjuvant therapy with lapatinib and trastuzumab, while hormone receptor-positive patients also received letrozole or tamoxifen [80]. Sixty-five percent of patients were in the HER2-E subgroup and $\mathrm{PCR}$ in this group was significantly higher than in the other subgroups (35.1 vs. 9.9\%). A positive correlation with $\mathrm{pCR}$ was also seen in the HER2-high group (36.1 vs. 8.2\%) [80]. The combination of the two biomarkers identified almost $50 \%$ of all patients who achieved pCR with targeted therapy. However, these biomarkers still remain to be studied in prospective randomised trials.

While on the one hand the APHINITY study confirmed the use of dual therapy with pertuzumab and trastuzumab in patients with a HER2-positive breast cancer and high risk [81], efforts are still on-going to achieve de-escalation of the therapy. Thus, in the APT study, the use of trastuzumab with 12-week monotherapy with paclitaxel was investigated and revealed disease-free survival (DFS) of $93.3 \%$ after 7 years in the node-negative cohort with a tumour size of less than $3 \mathrm{~cm}[82,83]$. A further fundamental question relating to de-escalation, as well as to everyday clinical practice, is the use of trastuzumab entirely without chemotherapy - particularly in elderly patients with comorbidities. The current data in this respect were insufficient. In the RESPECT study, 275 70-to 80-year-old patients with HER2-positive breast cancer and a tumour size of $5 \mathrm{~mm}$ and over were randomised to treatment with trastuzumab alone or in combination with chemotherapy at the doctor's discretion [84]. The median age was 73.5 years. The 3 -year DFS was $94.8 \%$ in the combination group and $89.2 \%$ in the monotherapy group (HR 1.42 [95\% Cl 0.68-2.95]; $\mathrm{p}=0.35$ ). The authors concluded, however, that the smaller number of events (18 vs. 12) substantially restricted the exact evaluation of the monotherapy. However, they calculated that, by refraining from chemotherapy, the life expectancy after 3 years is reduced by only one month and that therefore this can offer an adjuvant option for the elderly patient [84].

Numerous studies have also investigated the option of shortened trastuzumab therapy to reduce both toxicity and costs after the HERA study had shown no benefit for two-year treatment with trastuzumab over one-year treatment [85]. Previous studies such as the SOLD study ( 9 weeks of trastuzumab), the PHARE study ( 6 months of trastuzumab) or the ShortHer study ( 9 weeks of trastuzumab) failed to confirm non-inferiority of the shortened anti-HER2 therapy $[86,87]$. In the PERSEPHONE multicentre phase III study, the non-inferiority of a 6-month treatment was again investigated versus 12 months in a large cohort of 4,089 patients [88]. Patients with HER2-positive breast cancer and an indication for chemotherapy were included up to the 10th cycle of trastuzumab. After a median follow-up of 5.4 years, no significant difference was found in the 4-year DFS (89.4 vs. 89.8\%, HR 1.07 [95\% Cl 0.93-1.24]). Non-inferiority of the shortened treatment was also confirmed in terms of overall survival (93.8 vs. $94.8 \%$, HR 1.14 [95\% Cl 0.95-1.37]) [88]. In addition, premature treatment discontinuation due to cardiotoxicity was significantly reduced ( 4 vs. $8 \%, p<0.0001$ ). However, subgroup analysis revealed cohorts that benefit from the 12-month therapy, namely oestrogen receptor-negative patients, those receiving purely taxane-containing chemotherapy, patients treated with neoadjuvant therapy and patients with concomitant trastuzumab administration ( $\bullet$ Fig. 1).

\section{Prognostic and Predictive Markers}

Improving predictions of the prognosis for breast cancer patients has occupied science for some time now. In addition to the improved prediction of prognosis by means of prediction models $[89,90]$, the introduction of multigene tests has been one of the great advances of the last two decades [91-98].

Long-term data on the prognostic and predictive value of a 21-gene expression assay (Oncotype DX Recurrence Score) in hormone receptor-positive HER2-negative, node-negative breast cancer were recently presented in connection with the TAILOR-X study [93]. It had previously been known from earlier analyses that the test procedure can give the prognostic value of the risk 


\begin{tabular}{|c|c|c|c|c|c|}
\hline & \multicolumn{2}{|c|}{ Events/patients } & \multirow{2}{*}{\multicolumn{2}{|c|}{$\begin{array}{l}\text { Hazard Ratio and } 95 \% \mathrm{Cl} \\
\text { (6 months: } 12 \text { months) }\end{array}$}} & \multirow{2}{*}{$\begin{array}{l}\text { Hazard Ratio and } 95 \% \mathrm{Cl} \\
\text { (6 months : } 12 \text { months) }\end{array}$} \\
\hline & 6 months & 12 months & & & \\
\hline \multicolumn{6}{|l|}{ ER } \\
\hline Negative & $121 / 632(19.1 \%)$ & $99 / 633(15.6 \%)$ & & 与 & $1.26(0.97,1.64)$ \\
\hline Positive & $144 / 1411(10.2 \%)$ & $148 / 1412(10.5 \%)$ & & & $0.96(0.76,1.20)$ \\
\hline Stratified & $265 / 2043(13.0 \%)$ & $247 / 2045(12.1 \%)$ & & & $1.08(0.91,1.28)$ \\
\hline \multicolumn{6}{|c|}{ Interaction between 2 groups $x^{2}{ }_{1}=2.3 ; p=0.13$} \\
\hline \multicolumn{6}{|l|}{ CT type } \\
\hline Anthracycline-based & $93 / 846(11.0 \%)$ & $108 / 854(12.6 \%)$ & & & $0.86(0.65,1.13)$ \\
\hline Taxane-based & $28 / 203(13.8 \%)$ & $11 / 200(5.5 \%)$ & & $\square \square$ & $2.47(1.31,4.62)$ \\
\hline Anthracycline + taxane & $144 / 991$ (14.5\%) & $127 / 989(12.8 \%)$ & & & $1.14(0.90,1.44)$ \\
\hline Neither & $0 / 3(0.0 \%)$ & $1 / 2(50.0 \%)$ & 4 & & \\
\hline Stratified & $265 / 2043(13.0 \%)$ & $247 / 2045(12.1 \%)$ & & & $1.07(0.90,1.28)$ \\
\hline \multicolumn{6}{|c|}{ Heterogeneity between 4 groups $x^{2} 3=11.1 ; p=0.01$} \\
\hline \multicolumn{6}{|l|}{ CT timing } \\
\hline Adjuvant & $194 / 1731(11.2 \%)$ & $197 / 1737(11.3 \%)$ & & & $0.98(0.81,1.20)$ \\
\hline Neo-adjuvant & $71 / 312(22.8 \%)$ & $50 / 308(16.2 \%)$ & & - & $1.43(1.00,2.04)$ \\
\hline Stratified & $265 / 2043(13.0 \%)$ & $247 / 2045(12.1 \%)$ & & & $1.07(0.90,1.28)$ \\
\hline \multicolumn{6}{|c|}{ Interaction between 2 groups $x^{2} 1=3.2 ; p=0.07$} \\
\hline \multicolumn{6}{|l|}{ Trastuzumab timing } \\
\hline Concurrent (with CT) & $123 / 952(12.9 \%)$ & $82 / 951(8.6 \%)$ & & ᄀ & $1.53(1.16,2.01)$ \\
\hline Sequential (after CT) & $142 / 1091(13.0 \%)$ & $165 / 1094(15.1 \%)$ & & & $0.84(0.68,1.06)$ \\
\hline Stratified & $265 / 2043(13.0 \%)$ & $247 / 2045(12.1 \%)$ & & & $1.07(0.90,1.27)$ \\
\hline \multicolumn{6}{|c|}{ Interaction between 2 groups $x^{2} 1=10.8 ; p<0.001$} \\
\hline \multirow[t]{3}{*}{ Unstratified } & $265 / 2043(13.0 \%)$ & $247 / 2045(12.1 \%)$ & & & $1.07(0.90,1.28)$ \\
\hline & & & 0.1 & 0.20 .30 .40 .5 & 10 \\
\hline & & & & 12 months better & \\
\hline
\end{tabular}

- Fig. 1 Planned subgroup analyses in the PERSEPHONE study in respect of disease-free survival (DFS), modified after [88].

of recurrence in a low-risk cohort (Recurrence Score/RS 0-10) with endocrine therapy alone, as well as the predictive value in patients with a high risk (greater than/equal to 26) following chemotherapy [94]. In the prospective randomised study, data for the intermediate risk population (RS 11-25) have recently been presented: endocrine vs. chemoendocrine therapy was administered in these patients (between the ages of 18 and 75 years) in a randomised comparison. The primary endpoint was defined as invasive disease-free survival (iDFS) and the study was designed to demonstrate a potential non-inferiority of endocrine therapy alone. The data sets of a total of 10253 patients were analysed. Of these, 6711 (65.5\%) had an RS of between 11 and 25. There were 836 DFS events after a follow-up of 90 months. In the group of endocrine-only treated patients, the iDFS was $83.3 \%$ and in the group of patients with sequential chemoendocrine therapy was $84.3 \%$. Administration of endocrine therapy alone was therefore not inferior in the analyses and in the intention-to-treat (ITT) group compared to the combined administration of chemotherapy and endocrine therapy in terms of iIDFS (HR 1.08, $95 \% \mathrm{Cl}$ $0.94,1.24, p=0.26$ ) [93]. Administration of endocrine therapy alone was also not inferior on other endpoints such as distant re- currence-free interval (DRFI; HR 1.03, $p=0.80)$, recurrence-free interval (RFI; HR 1.12; $p=0.28$ ) and overall survival (OS, HR 0.97, $\mathrm{p}=0.80$ ) in patients aged over 50 years and with an RS of $11-25$ and in patients under 50 years with an RS of 11-15. Although this randomised comparison offers suggestions for the planning of endocrine or chemoendocrine therapy through the presentation of long-term data for the intermediate group, the conventional (pathological) prognostic and predictive factors should initially take precedence in treatment planning in routine clinical practice.

\section{Acknowledgements}

This article arose partly as a result of grants by Hexal and the PRAEGNANT network, which had no part in the writing of this manuscript. The authors alone are responsible for the content of the manuscript.

\section{Conflict of Interest}

A. D. H. received honoraria from AstraZeneca, Genomic Health, Roche, Novartis, Celgene and Pfizer. N. N. received consultancy honoraria from Janssen-Cilag and travel support from Novartis. F. O. received speaker and consultancy honoraria from Amgen, Celgene, TEVA, AstraZeneca, 
Novartis, Roche, and MSD. F.-A. T. received honoraria from AstraZeneca, Genomic Health and Novartis. H.-C. K. received honoraria from Carl Zeiss meditec, TEVA, Theraclion, Novartis, Amgen, AstraZeneca, Pfizer, Janssen-Cilag, GSK, LIV Pharma, Roche and Genomic Health. P. H. received honoraria, unrestricted educational grants and research funding from Amgen, AstraZeneca, Eli Lilly, MSD, Novartis, Pfizer and Roche. P. A. F. received honoraria from Roche, Pfizer, Novartis and Celgene. His institution conducts research for Novartis. H. T. received honoraria from Novartis, Roche, Celgene, TEVA, Pfizer and travel support from Roche, Celgene and Pfizer. J. E. received honoraria from Roche, Celgene, Novartis, Pfizer, Pierre Fabre, TEVA and travel support from Celgene, Pfizer, TEVA and Pierre Fabre. M.P. L. has participated on advisory boards for AstraZeneca, MSD, Novartis, Pfizer, Genomic Health and Roche and has received honoraria for lectures from MSD, Lilly, Roche, Novartis, Pfizer, Genomic Health, AstraZeneca, medac and Eisai. V. M. received speaker honoraria from Amgen, AstraZeneca, Celgene, Daiichi Sankyo, Eisai, Pfizer, Pierre-Fabre, Novartis, Roche, Teva, Janssen-Cilag and consultancy honoraria from Genomic Health, Roche, Pierre Fabre, Amgen, Daiichi-Sankyo and Eisai. E. B. received honoraria from Novartis and Hexal for consulting and clinical research management activities. A.S. received honoraria from Roche, Celgene, AstraZeneca, Novartis, Pfizer, Zuckschwerdt Verlag GmbH, Georg Thieme Verlag, Aurikamed $\mathrm{GmbH}, \mathrm{MCl}$ Deutschland $\mathrm{GmbH}$, bsh medical communications $\mathrm{GmbH}$ and promedicis $\mathrm{GmbH}$. W.J. received honoraria and research grants from Novartis, Roche, Pfizer, Lilly, AstraZeneca, Chugai, Sanofi, Daiichi Sankyo and Tesaro. F. S. participated on advisory boards for Novartis, Lilly, Amgen and Roche and received honoraria for lectures from Roche, AstraZeneca, MSD, Novartis and Pfizer. A. W. participated on advisory boards for Novartis, Amgen, Pfizer, Roche, Tesaro, Eisai and received honoraria for lectures from Novartis, Pfizer, Aurikamed, Roche, Celgene. D. L. received honorarium from Amgen, AstraZeneca, Celgene, Lilly, Loreal, MSD, Novartis, Pfizer, Tesaro M. W. received speakers honoraria and consultant fees from Novartis, Amgen, Celgene, Roche, Genentech, AstraZeneca, and Pfizer. S. Y. B. received honoraria from Pfizer, and Novartis. T. N. F. has participated on advisory boards for Amgen, Daiichi Sankyo, Novartis, Pfizer, and Roche and has received honoraria for lectures from Celgene, Roche, Novartis and Pfizer.

\section{References}

[1] Taran FA, Schneeweiss A, Lux MP et al. Update Breast Cancer 2018 (Part 1) - Primary Breast Cancer and Biomarkers. Geburtsh Frauenheilk 2018; 78: $237-245$

[2] Schneeweiss A, Lux MP, Janni W et al. Update Breast Cancer 2018 (Part 2) - Advanced Breast Cancer, Quality of Life and Prevention. Geburtsh Frauenheilk 2018; 78: 246-259

[3] Untch M, Wurstlein R, Marschner $\mathrm{N}$ et al. 4th International Consensus Conference on Advanced Breast Cancer (ABC4), Lisbon, November 4, 2017: ABC4 Consensus: Assessment by a Panel of German Experts. Geburtsh Frauenheilk 2018; 78: 469-480

[4] Ghoussaini M, Fletcher O, Michailidou K et al. Genome-wide association analysis identifies three new breast cancer susceptibility loci. Nat Genet 2012; 44: 312-318

[5] Michailidou K, Beesley J, Lindstrom S et al. Genome-wide association analysis of more than 120,000 individuals identifies 15 new susceptibility loci for breast cancer. Nat Genet 2015; 47: 373-380

[6] Michailidou K, Hall P, Gonzalez-Neira A et al. Large-scale genotyping identifies 41 new loci associated with breast cancer risk. Nat Genet 2013; 45: 353-361, 361.e1-361.e2

[7] Michailidou K, Lindstrom S, Dennis J et al. Association analysis identifies 65 new breast cancer risk loci. Nature 2017; 551: 92-94

[8] Ahmed S, Thomas G, Ghoussaini M et al. Newly discovered breast cancer susceptibility loci on 3p24 and 17q23.2. Nat Genet 2009; 41: 585-590
[9] Antoniou AC, Wang X, Fredericksen ZS et al. A locus on 19p13 modifies risk of breast cancer in BRCA1 mutation carriers and is associated with hormone receptor-negative breast cancer in the general population. Nat Genet 2010; 42: 885-892

[10] Bojesen SE, Pooley KA, Johnatty SE et al. Multiple independent variants at the TERT locus are associated with telomere length and risks of breast and ovarian cancer. Nat Genet 2013; 45: 371-384, 384e1-384e2

[11] Cox A, Dunning AM, Garcia-Closas M et al. A common coding variant in CASP8 is associated with breast cancer risk. Nat Genet 2007; 39: 352358

[12] Easton DF, Pooley KA, Dunning AM et al. Genome-wide association study identifies novel breast cancer susceptibility loci. Nature 2007; 447: 1087-1093

[13] Fasching PA, Ekici AB, Adamietz BR et al. Breast Cancer Risk - Genes, Environment and Clinics. Geburtsh Frauenheilk 2011; 71: 1056-1066

[14] Fasching PA, Ekici AB, Wachter DL et al. Breast Cancer Risk - From Genetics to Molecular Understanding of Pathogenesis. Geburtsh Frauenheilk 2013; 73: 1228-1235

[15] Fletcher O, Johnson N, Orr N et al. Novel breast cancer susceptibility locus at 9q31.2: results of a genome-wide association study. J Natl Cancer Inst 2011; 103: 425-435

[16] French JD, Ghoussaini M, Edwards SL et al. Functional variants at the $11 \mathrm{q} 13$ risk locus for breast cancer regulate cyclin D1 expression through long-range enhancers. Am J Hum Genet 2013; 92: 489-503

[17] Garcia-Closas M, Couch F], Lindstrom S et al. Genome-wide association studies identify four ER negative-specific breast cancer risk loci. Nat Genet 2013; 45: 392-398, 398e1-398e2

[18] Haiman CA, Chen GK, Vachon CM et al. A common variant at the TERTCLPTM1 $\mathrm{L}$ locus is associated with estrogen receptor-negative breast cancer. Nat Genet 2011; 43: 1210-1214

[19] Milne RL, Benitez ], Nevanlinna H et al. Risk of estrogen receptor-positive and -negative breast cancer and single-nucleotide polymorphism 2q35rs13387042. J Natl Cancer Inst 2009; 101: 1012-1018

[20] Milne RL, Kuchenbaecker KB, Michailidou K et al. Identification of ten variants associated with risk of estrogen-receptor-negative breast cancer. Nat Genet 2017; 49: 1767-1778

[21] Siddiq A, Couch F], Chen GK et al. A meta-analysis of genome-wide association studies of breast cancer identifies two novel susceptibility loci at 6q14 and 20q11. Hum Mol Genet 2012; 21: 5373-5384

[22] Stacey SN, Manolescu A, Sulem P et al. Common variants on chromosomes $2 \mathrm{q} 35$ and $16 \mathrm{q} 12$ confer susceptibility to estrogen receptor-positive breast cancer. Nat Genet 2007; 39: 865-869

[23] Stacey SN, Manolescu A, Sulem P et al. Common variants on chromosome $5 p 12$ confer susceptibility to estrogen receptor-positive breast cancer. Nat Genet 2008; 40: 703-706

[24] Stevens KN, Fredericksen Z, Vachon CM et al. 19p13.1 is a triple-negative-specific breast cancer susceptibility locus. Cancer Res 2012; 72: 1795-1803

[25] Thomas G, Jacobs KB, Kraft P et al. A multistage genome-wide association study in breast cancer identifies two new risk alleles at 1p11.2 and 14q24.1 (RAD51L1). Nat Genet 2009; 41: 579-584

[26] Turnbull C, Ahmed S, Morrison J et al. Genome-wide association study identifies five new breast cancer susceptibility loci. Nat Genet 2010; 42: 504-507

[27] Wunderle M, Olmes G, Nabieva N et al. Risk, Prediction and Prevention of Hereditary Breast Cancer - Large-Scale Genomic Studies in Times of Big and Smart Data. Geburtsh Frauenheilk 2018; 78: 481-492

[28] Zheng W, Long J, Gao YT et al. Genome-wide association study identifies a new breast cancer susceptibility locus at 6q25.1. Nat Genet 2009; 41: 324-328 
[29] Purrington KS, Slager S, Eccles D et al. Genome-wide association study identifies 25 known breast cancer susceptibility loci as risk factors for triple-negative breast cancer. Carcinogenesis 2014; 35: 1012-1019

[30] Stevens KN, Fredericksen Z, Vachon CM et al. 19p13.1 is a triple-negative-specific breast cancer susceptibility locus. Cancer Res 2012; 72: 1795-1803

[31] Vachon CM, Scott CG, Fasching PA et al. Common breast cancer susceptibility variants in LSP1 and RAD51L1 are associated with mammographic density measures that predict breast cancer risk. Cancer Epidemiol Biomarkers Prev 2012; 21: 1156-1166

[32] Garcia-Closas M, Gunsoy NB, Chatterjee N. Combined associations of genetic and environmental risk factors: implications for prevention of breast cancer. J Natl Cancer Inst 2014; 106: pii: dju305. doi:10.1093/ jnci/dju305

[33] Mavaddat N, Pharoah PD, Michailidou K et al. Prediction of breast cancer risk based on profiling with common genetic variants. J Natl Cancer Inst 2015; 107: pii: djv036. doi:10.1093/jnci/djv036

[34] Vachon CM, Pankratz VS, Scott CG et al. The contributions of breast density and common genetic variation to breast cancer risk. J Natl Cancer Inst 2015; 107: pii: dju397. doi:10.1093/jnci/dju397

[35] Rudolph A, Song M, Brook MN et al. Joint associations of a polygenic risk score and environmental risk factors for breast cancer in the Breast Cancer Association Consortium. Int J Epidemiol 2018. doi:10.1093/ije/ dyx242

[36] Haberle L, Hein A, Rubner M et al. Predicting Triple-Negative Breast Cancer Subtype Using Multiple Single Nucleotide Polymorphisms for Breast Cancer Risk and Several Variable Selection Methods. Geburtsh Frauenheilk 2017; 77: 667-678

[37] Simard J, Chiarelli AM. Personalized risk assessment for prevention and early detection of breast cancer: Integration and Implementation. 2018. Online: https://www.genomecanada.ca/sites/default/files/ 2017lsarp_backgrounder_en.pdf; last access: 01.04.2018

[38] Unicancer. Randomized, Comparison Of Risk-Stratified versus Standard Breast Cancer Screening In European Women Aged 40-74. 2017. Online: https://cordis.europa.eu/project/rcn/212694_en.html; last access: 01.04.2018

[39] Shieh Y, Eklund M, Madlensky L et al. Breast Cancer Screening in the Precision Medicine Era: Risk-Based Screening in a Population-Based Trial. J Natl Cancer Inst 2017. doi:10.1093/jnci/djw290

[40] Evans DG, Astley S, Stavrinos P et al. Improvement in risk prediction, early detection and prevention of breast cancer in the NHS Breast Screening Programme and family history clinics: a dual cohort study. Southampton (UK): NIHR Journals Library; 2016

[41] ASSURE Consortium. Final Report Summary - ASSURE (Adapting Breast Cancer Screening Strategy Using Personalised RiskEstimation). 2016. Online: https://cordis.europa.eu/result/rcn/187468_en.html; last access: 01.04.2018

[42] Couch FJ, Hart SN, Sharma P et al. Inherited mutations in 17 breast cancer susceptibility genes among a large triple-negative breast cancer cohort unselected for family history of breast cancer. J Clin Oncol 2015; 33: 304-311

[43] Couch F], Shimelis H, Hu C et al. Associations Between Cancer Predisposition Testing Panel Genes and Breast Cancer. JAMA Oncol 2017; 3: 1190-1196

[44] Fasching PA, Loibl S, Hu C et al. BRCA1/2 Mutations and Bevacizumab in the Neoadjuvant Treatment of Breast Cancer: Response and Prognosis Results in Patients With Triple-Negative Breast Cancer From the GeparQuinto Study. J Clin Oncol 2018. doi:10.1200/JCO.2017.77.2285

[45] Wunderle M, Gass P, Haberle L et al. BRCA mutations and their influence on pathological complete response and prognosis in a clinical cohort of neoadjuvantly treated breast cancer patients. Breast Cancer Res Treat 2018; 171: 85-94
[46] Fasching PA, Hu C, Hart SN et al. Cancer predisposition genes in metastatic breast cancer - Association with metastatic pattern, prognosis, patient and tumor characteristics [abstract]. In: Proceedings of the 2017 San Antonio Breast Cancer Symposium; 2017 Dec 5-9; San Antonio, TX. Philadelphia (PA): AACR; Cancer Res 2018; 78: Abstr. PD1-02

[47] Nolan E, Vaillant F, Branstetter D et al. RANK ligand as a potential target for breast cancer prevention in BRCA1-mutation carriers. Nat Med 2016; 22: 933-939

[48] Sigl V, Jones LP, Penninger JM. RANKL/RANK: from bone loss to the prevention of breast cancer. Open Biol 2016; 6: pii: 160230

[49] Sigl V, Owusu-Boaitey K, Joshi PA et al. RANKL/RANK control Brca1 mutation-driven mammary tumors. Cell Res 2016; 26: 761-774

[50] Bayer CM, Beckmann MW, Fasching PA. Updates on the role of receptor activator of nuclear factor kappaB/receptor activator of nuclear factor kappaB ligand/osteoprotegerin pathway in breast cancer risk and treatment. Curr Opin Obstet Gynecol 2017; 29: 4-11

[51] Francis P, Singer C, Saunders C et al. BRCA-P: An international randomised phase III study evaluating the RANK ligand inhibitor denosumab for the prevention of breast cancer in BRCA1 mutation carriers [20182022]. Online: http://purlorg/au-research/grants/nhmrc/1140715 and https://researchdataandsorgau/brca-p-an-mutation-carriers/1319302 2018; last access: 02.04.2018

[52] Kuchenbaecker KB, Hopper JL, Barnes DR et al. Risks of Breast, Ovarian, and Contralateral Breast Cancer for BRCA1 and BRCA2 Mutation Carriers. JAMA 2017; 317: 2402-2416

[53] Copson ER, Maishman TC, Tapper W] et al. Germline BRCA mutation and outcome in young-onset breast cancer ( $\mathrm{POSH}$ ): a prospective cohort study. Lancet Oncol 2018. doi:10.1016/S1470-2045(17)30891-4

[54] Fasching PA. Breast cancer in young women: do BRCA1 or BRCA2 mutations matter? Lancet Oncol 2018. doi:10.1016/S1470-2045(18)30008-1

[55] Evron E, Ben David MA, Goldberg $\mathrm{H}$ et al. Phase II national clinical trial of prophylactic irradiation to the contralateral breast for BRCA mutation carriers treated for early breast cancer (EBC). J Clin Oncol 2018; 36 (Suppl.): Abstr. 514

[56] Poortmans PM, Collette S, Kirkove C et al. Internal Mammary and Medial Supraclavicular Irradiation in Breast Cancer. N Engl J Med 2015; 373 . 317-327

[57] Poortmans P, Collette S, Struikmans $\mathrm{H}$ et al. Fifteen-year results of the randomised EORTC trial 22922/10925 investigating internal mammary and medial supraclavicular (IM-MS) lymph node irradiation in stage I-III breast cancer. J Clin Oncol 2018; 36 (Suppl.): Abstr. 504

[58] Herrera FG, Bourhis ], Coukos G. Radiotherapy combination opportunities leveraging immunity for the next oncology practice. CA Cancer J Clin 2017; 67: 65-85

[59] McArthur HL, Barker CA, Gucalp A et al. A phase II, single arm study assessing the efficacy of pembrolizumab (Pembro) plus radiotherapy (RT) in metastatic triple negative breast cancer (mTNBC). J Clin Oncol 2018; 36 (Suppl.): Abstr. 1017

[60] Formenti SC, Golden EB, Goldberg JD et al. Results of a phase I-II study of adjuvant concurrent carboplatin and accelerated radiotherapy for triple negative breast cancer. Oncoimmunology 2017; 6: e1274479

[61] Ngwa W, Irabor OC, Schoenfeld JD et al. Using immunotherapy to boost the abscopal effect. Nat Rev Cancer 2018; 18: 313-322

[62] Davies C, Godwin J, Gray R et al.; Early Breast Cancer Trialists' Collaborative Group. Relevance of breast cancer hormone receptors and other factors to the efficacy of adjuvant tamoxifen: patient-level meta-analysis of randomised trials. Lancet $2011 ; 378: 771-784$

[63] Early Breast Cancer Trialists' Collaborative Group. Aromatase inhibitors versus tamoxifen in early breast cancer: patient-level meta-analysis of the randomised trials. Lancet 2015; 386: 1341-1352

[64] Pagani O, Regan MM, Walley BA et al. Adjuvant exemestane with ovarian suppression in premenopausal breast cancer. N Engl J Med 2014; 371: $107-118$ 
[65] Francis PA, Regan MM, Fleming GF et al. Adjuvant ovarian suppression in premenopausal breast cancer. N Engl J Med 2015; 372: 436-446

[66] Francis PA, Pagani O, Fleming GF et al. Tailoring Adjuvant Endocrine Therapy for Premenopausal Breast Cancer. N Engl J Med 2018; 379: 122-137

[67] Regan MM, Francis PA, Pagani O et al. Absolute improvements in freedom from distant recurrence with adjuvant endocrine therapies for premenopausal women with hormone receptor-positive (HR+) HER2-negative breast cancer (BC): Results from TEXT and SOFT. J Clin Oncol 2018; 36 (Suppl.): Abstr. 503

[68] Noh WC, Lee JW, Nam SJ et al. Role of adding ovarian function suppression to tamoxifen in young women with hormone-sensitive breast cancer who remain premenopausal or resume menstruation after chemotherapy: The ASTRRA study. J Clin Oncol 2018; 36 (Suppl.): Abstr. 502

[69] Leitlinienprogramm Onkologie (Deutsche Krebsgesellschaft und Deutsche Krebshilfe und AWMF). S3-Leitlinie Früherkennung, Diagnose, Therapie und Nachsorge des Mammakarzinoms, Version 4.0, 2017 AWMF Registernummer: 032-045OL. 2017. Online: http://www.leitlinienprogrammonkologie.de/leitlinien/mammakarzinom/; last access: 23.07.2018

[70] Early Breast Cancer Trialists' Collaborative Group. Adjuvant bisphosphonate treatment in early breast cancer: meta-analyses of individual patient data from randomised trials. Lancet 2015; 386: 1353-1361

[71] Gnant M, Pfeiler G, Dubsky PC et al. The impact of adjuvant denosumab on disease-free survival: Results from 3,425 postmenopausal patients of the ABCSG-18 trial. Cancer Res 2016; 76 (Suppl. 4): Abstract S2-02

[72] Coleman RE, Finkelstein D, Barrios CH et al. Adjuvant denosumab in early breast cancer: First results from the international multicenter randomized phase III placebo controlled D-CARE study. J Clin Oncol 2018; 36 (Suppl.): Abstr. 501

[73] Gnant M, Pfeiler G, Steger GG et al. Adjuvant denosumab in early breast cancer: Disease-free survival analysis of 3,425 postmenopausal patients in the ABCSG-18 trial. J Clin Oncol 2018; 36 (Suppl.): Abstr. 500

[74] Early Breast Cancer Trialists' Collaborative Group. Long-term outcomes for neoadjuvant versus adjuvant chemotherapy in early breast cancer: meta-analysis of individual patient data from ten randomised trials. Lancet Oncol 2018; 19: 27-39

[75] Cortazar P, Zhang L, Untch M et al. Pathological complete response and long-term clinical benefit in breast cancer: the $C T N e o B C$ pooled analysis. Lancet 2014; 384: 164-172

[76] Fasching PA, Heusinger K, Haeberle L et al. Ki67, chemotherapy response, and prognosis in breast cancer patients receiving neoadjuvant treatment. BMC Cancer 2011; 11: 486

[77] von Minckwitz G, Untch M, Blohmer JU et al. Definition and impact of pathologic complete response on prognosis after neoadjuvant chemotherapy in various intrinsic breast cancer subtypes. J Clin Oncol 2012; 30: $1796-1804$

[78] Gianni L, Pienkowski T, Im YH et al. 5-year analysis of neoadjuvant pertuzumab and trastuzumab in patients with locally advanced, inflammatory, or early-stage HER2-positive breast cancer (NeoSphere): a multicentre, open-label, phase 2 randomised trial. Lancet Oncol 2016; 17: $791-800$

[79] Guarneri V, Dieci MV, Bisagni G et al. De-escalated treatment with trastuzumab-pertuzumab-letrozole in patients with HR+/HER2+ operable breast cancer with Ki67 response after 2 weeks letrozole: Final results of the PerELISA neoadjuvant study. J Clin Oncol 2018; 36 (Suppl.): Abstr. 507

[80] Prat A, De Angelis C, Pascual T et al. HER2-enriched subtype and ERBB2 $m R N A$ as predictors of pathological complete response following trastuzumab and lapatinib without chemotherapy in early-stage HER2positive breast cancer: A combined analysis of TBCRC006/023 and PAMELA trials. J Clin Oncol 2018; 36 (Suppl.): Abstr. 509

[81] von Minckwitz G, Procter M, de Azambuja E et al. Adjuvant Pertuzumab and Trastuzumab in Early HER2-Positive Breast Cancer. N Engl J Med 2017; 377: 122-131
[82] Tolaney SM, Barry WT, Dang CT et al. Adjuvant paclitaxel and trastuzumab for node-negative, HER2-positive breast cancer. N Engl J Med 2015; 372: 134-141

[83] Tolaney SM, Barry WT, Guo H et al. Seven-year (yr) follow-up of adjuvant paclitaxel $(\mathrm{T})$ and trastuzumab (H) (APT trial) for node-negative, HER2positive breast cancer (BC). J Clin Oncol 2017; 35: 511

[84] Sawaki M, Saito T, Baba S et al. Evaluation of trastuzumab without chemotherapy as a postoperative adjuvant therapy in HER2-positive elderly breast cancer patients: Randomized controlled trial (RESPECT). J Clin Oncol 2018; 36 (Suppl.): Abstr. 510

[85] Cameron D, Piccart-Gebhart M], Gelber RD et al. 11 years' follow-up of trastuzumab after adjuvant chemotherapy in HER2-positive early breast cancer: final analysis of the HERceptin Adjuvant (HERA) trial. Lancet 2017; 389: 1195-1205

[86] Pivot X, Romieu G, Debled M et al. 6 months versus 12 months of adjuvant trastuzumab for patients with HER2-positive early breast cancer (PHARE): a randomised phase 3 trial. Lancet Oncol 2013; 14: 741-748

[87] Joensuu H, Fraser J, Wildiers $\mathrm{H}$ et al. Effect of Adjuvant Trastuzumab for a Duration of 9 Weeks vs. 1 Year With Concomitant Chemotherapy for Early Human Epidermal Growth Factor Receptor 2-Positive Breast Cancer: The SOLD Randomized Clinical Trial. JAMA Oncol 2018. doi:10.1001/jamaoncol.2018.1380

[88] Earl HM, Hiller L, Vallier AL et al. PERSEPHONE: 6 versus 12 months ( $m$ ) of adjuvant trastuzumab in patients (pts) with HER2 positive (+) early breast cancer (EBC): Randomised phase 3 non-inferiority trial with definitive 4-year (yr) disease-free survival (DFS) results. J Clin Oncol 2018; 36 (Suppl.): Abstr. 506

[89] Ravdin PM, Siminoff LA, Davis G] et al. Computer program to assist in making decisions about adjuvant therapy for women with early breast cancer. J Clin Oncol 2001; 19: 980-991

[90] Wishart GC, Bajdik CD, Dicks E et al. PREDICT Plus: development and validation of a prognostic model for early breast cancer that includes HER2. Br J Cancer 2012; 107: 800-807

[91] Cardoso F, van't Veer LJ, Bogaerts J et al. 70-Gene Signature as an Aid to Treatment Decisions in Early-Stage Breast Cancer. N Engl J Med 2016; 375: 717-729

[92] Paik S, Shak S, Tang G et al. A multigene assay to predict recurrence of tamoxifen-treated, node-negative breast cancer. N Engl J Med 2004; 351: $2817-2826$

[93] Sparano JA, Gray RJ, Makower DF et al. Adjuvant Chemotherapy Guided by a 21-Gene Expression Assay in Breast Cancer. N Engl J Med 2018; 379: $111-121$

[94] Sparano JA, Gray RJ, Makower DF et al. Prospective Validation of a 21Gene Expression Assay in Breast Cancer. N Engl J Med 2015; 373: 20052014

[95] Cuzick J, Dowsett M, Pineda S et al. Prognostic value of a combined estrogen receptor, progesterone receptor, $\mathrm{Ki}-67$, and human epidermal growth factor receptor 2 immunohistochemical score and comparison with the Genomic Health recurrence score in early breast cancer. J Clin Oncol 2011; 29: 4273-4278

[96] Dowsett M, Sestak I, Lopez-Knowles E et al. Comparison of PAM50 risk of recurrence score with oncotype DX and IHC4 for predicting risk of distant recurrence after endocrine therapy. J Clin Oncol 2013; 31: 27832790

[97] Filipits M, Rudas M, Jakesz R et al. A new molecular predictor of distant recurrence in ER-positive, HER2-negative breast cancer adds independent information to conventional clinical risk factors. Clin Cancer Res 2011; 17: 6012-6020

[98] Schmidt M, Fasching PA, Beckmann MW et al. Biomarkers in Breast Cancer - An Update. Geburtsh Frauenheilk 2012; 72: 819-832 